\title{
A EDUCAÇÃO AMBIENTAL EM CURSOS DE FORMAÇÃO INICIAL DE PROFESSORES: ANÁLISE DE PROJETOS PEDAGÓGICOS DE DOIS CURSOS DE LICENCIATURA EM FÍSICA
}

\author{
ENVIRONMENTAL EDUCATION AND INITIAL TEACHER TRAINING: ANALYSIS OF \\ PEDAGOGICAL PROJECTS OF TWO PHYSICS TEACHER EDUCATION COURSES
}

\section{EDUCACIÓN AMBIENTAL EN CURSOS DE FORMACIÓN DEL PROFESORADO: ANÁLISIS DE PROYECTOS PEDAGÓGICOS DE DOS CURSOS DE GRADO EN FÍSICA}

Danielle Aparecida Reis Leite

E-mail: danielle.reis@uftm.edu.br

Universidade Federal do Triângulo Mineiro - UFTM

\begin{abstract}
RESUMO
A presença da temática ambiental em cursos de formação de professores recebe destaque na atualidade sendo, inclusive, recomendada por instrumentos normativos brasileiros, como a Política Nacional de Educação Ambiental e as Diretrizes Curriculares Nacionais para a Educação Ambiental. Nesse sentido, o objetivo principal deste trabalho é o de compreender como as recomendações para a inserção da Educação Ambiental (EA) na formação inicial de professores estabelecidas pela legislação brasileira materializam-se nos Projetos Pedagógicos de dois cursos de Licenciatura em Física oferecidos por duas Instituições de Ensino Superior públicas localizadas no estado de São Paulo. O material selecionado foi analisado segundo a perspectiva de Michel Foucault (1926-1984), por meio da mobilização dos conceitos de formação discursiva, poder e sujeito. Foi possível constatar que esses documentos se apropriam do discurso que trata da presença da EA na formação inicial dos docentes, entretanto a mesma é implementada de maneiras bastante distintas nesses dois cursos. Embora a formação discursiva sobre a EA defenda que a temática ambiental deva estar presente na formação de professores, foi possível constatar certa resistência às diretrizes oficiais que apresentam tais recomendações e que pode ser decorrente da relação de poder estabelecida entre os instrumentos normativos e os Projetos Pedagógicos analisados.
\end{abstract}

PALAVRAS-CHAVE: Licenciatura em Física. Educação ambiental. Ambientalização curricular.

\section{ABSTRACT}

The presence of the environmental theme in the teachers training have highlighted nowadays and is even recommended by Brazilian normative instruments, such as the National Environmental Education Policy and the National Curricular Guidelines for Environmental Education. In this sense, the main objective of this article is to understand how the recommendations about the insertion of Environmental Education (EE) in the initial teacher training that are established by the Brazilian legislation materialize in the Pedagogical Projects of two Physics teacher education courses offered by two public higher education institutions located in the state of São Paulo, Brazil. The selected material was analyzed according to the perspective of Michel Foucault (1926-1984), through the mobilization of the concepts related to discursive formation, power and subject. It was possible to verify that these documents appropriated the discourse that deals with the presence of the EE in the initial teachers training, however it is implemented in quite different ways in these two courses. Although the discursive formation on EE advocates that the environmental theme should be present in teachers training, it was possible to detect resistance to the official guidelines that present such recommendations and that may be due to the relation of power that is established between the normative instruments and the Pedagogical projects analyzed.

KEYWORDS: Physics Teacher Education Course. Environmental education. Curricular greening. 


\section{RESUMEN}

La presencia del tema ambiental en los cursos de grado para la formación del profesorado se destaca hoy e incluso es recomendada por instrumentos normativos brasileños, como la Política Nacional de Educación Ambiental y las Directrices Curriculares Nacionales para la Educación Ambiental. En este sentido, el objetivo principal de este trabajo es comprender cómo las recomendaciones para la inserción de la Educación Ambiental (EA) en la formación inicial de docentes establecida por la legislación brasileña se materializan en los Proyectos Pedagógicos de dos cursos de grado en formación del profesorado en Física ofrecidos por dos instituciones de educación superior ubicadas en el estado de São Paulo, Brasil. El material seleccionado fue analizado desde la perspectiva de Michel Foucault (1926-1984), a través de la movilización de los conceptos de formación discursiva, poder y sujeto. Fue posible verificar que estos documentos se apropian del discurso que trata sobre la presencia de EA en la formación inicial de los docentes, sin embargo, se implementa de maneras muy diferentes en estos dos cursos. Aunque la capacitación discursiva sobre EA argumente que el tema ambiental deba estar presente en la formación del profesorado, fue posible notar cierta resistencia a las pautas oficiales que presentan tales recomendaciones y que puede deberse a la relación de poder establecida entre los instrumentos normativos y los proyectos pedagógicos analizados.

PALABRAS-CLAVE: Formación del profesorado en fisica. Educación ambiental. Ambientalización Curricular.

\section{INTRODUÇÃO}

A questão ambiental é um tema de relevância nas discussões contemporâneas que têm sinalizado a necessidade de formar cidadãos críticos e engajados no enfrentamento dos problemas ambientais. Dentre as diferentes alternativas que visam contribuir com a superação do quadro de degradação ambiental cada vez mais acentuado, destaca-se a integração da temática ambiental e da Educação Ambiental (EA) nos currículos dos diferentes níveis de ensino (FRACALANZA, 2004; ZUIN; FARIAS; FREITAS, 2009; SILVA; FARIAS, 2017).

No Brasil, as recomendações para a abordagem da EA na Educação Básica e superior também são enfatizadas em âmbito legislativo. A Lei 6.938/81, Política Nacional do Meio Ambiente (PNMA), determina a inserção da EA em todos os níveis de ensino, com a intenção de capacitar a comunidade para a defesa do meio ambiente (BRASIL, 1981). Esse aspecto é reafirmado pela Constituição Federal de 1988 (CF/88) que designa ao Poder Público a incumbência de "promover a educação ambiental em todos os níveis de ensino e a conscientização pública para a preservação do meio ambiente" (BRASIL, 1988, p. 131). Também o é pela Lei 9.795/99, Política Nacional de Educação Ambiental (PNEA), a qual assegura que a EA deve ser "considerada um componente essencial e permanente da educação nacional, devendo estar presente, de forma articulada, em todos os níveis e modalidades do processo educativo, em caráter formal e não-formal” (BRASIL, 1999, p. 1).

No campo teórico, os pesquisadores indicam que o envolvimento dos professores é imprescindível para garantir a abordagem da temática ambiental e da EA nos diferentes níveis 
de ensino. Com isso, a necessidade de formar profissionais capacitados para esse desafio revela a importância de que os aspectos da EA e da temática ambiental sejam incorporados aos cursos de formação inicial e continuada de professores (CARVALHO, 2001; OLIVEIRA; CARVALHO, 2012; SILVA; FARIAS, 2017; LEITE, 2019; MIYAZAWA; FRENEDOZO; VIEIRA; 2019).

Dada a importância da EA e da temática ambiental para a formação de um professor, compreendemos que a abordagem desses temas nas licenciaturas deveria contribuir com a construção de posicionamentos críticos. Para além do tratamento de aspectos ecológicos, destacamos a relevância de que essas práticas formativas visem à problematização do atual modelo de desenvolvimento econômico-social, explorando as suas inter-relações com os campos político, econômico, social e científico. Além disso, a abordagem dos conhecimentos de EA nas licenciaturas requer a utilização de “[...] estratégias metodológicas flexíveis, multidimensionais, criativas e capazes de atender às unidades complexas, a fim de superar as dicotomias e polaridades existentes" (MOTIN et al., 2019, p. 84).

Tratando novamente da legislação brasileira, destacamos as recomendações para a presença da EA nos cursos de formação de professores. A PNEA garante que "A dimensão ambiental deve constar nos currículos de formação de professores, em todos os níveis e em todas as disciplinas" (BRASIL, 1999, p. 4). Por sua vez, as Diretrizes Curriculares Nacionais para a Educação Ambiental (DCNEA) enfatizam que os cursos de formação inicial e continuada de professores devem capacitá-los "para o desenvolvimento didático-pedagógico da dimensão da Educação Ambiental na sua atuação escolar e acadêmica” (BRASIL, 2012, p. 7).

Ao tratar da abordagem da temática ambiental no Ensino Superior, nos aproximamos do campo da ambientalização curricular. Não existe um consenso para a definição desse termo e é possível identificar na literatura diferentes significados para esse processo. Em uma perspectiva mais pontual, destaca-se que ambientalizar o currículo corresponde a "[...] um processo de inovação, que realiza mudanças no currículo através de intervenções que visam integrar temas socioambientais aos seus conteúdos e práticas" (KITZMANN; ASMUS, 2012, p. 270). Ruscheinsky (2014, p. 101) a descreve como “[...] o processo de acolher questões ambientais sob a lógica do nexo entre sociedade e Natureza e igualmente integradas em uma perspectiva interdisciplinar". Em definições mais ampliadas, a ambientalização curricular é caracterizada como o processo de "[...] inserção de conhecimentos, de critérios e de valores 
sociais, éticos, estéticos e ambientais nos estudos e currículos universitários, no sentido de educar para a sustentabilidade socioambiental" (GUERRA et al. 2015, p. 12).

Conforme destacado por Mota e Kitzmann (2018) e Kitzmann e Asmus (2012), a ambientalização curricular é complexa e solicita a mobilização e incorporação de saberes e práticas ambientais em um processo dialético com as concepções crítico-sociais da EA. Por isso, esses autores concordam que ambientalizar o currículo extrapola o ideal da simples inserção de temas ambientais isolados na grade curricular de determinado curso.

No âmago dessas discussões, são desenvolvidas diversas investigações que visam analisar diferentes aspectos relacionados com a abordagem da temática ambiental e/ou EA em cursos de licenciatura de áreas do conhecimento diversificadas. Como exemplo, citamos os trabalhos de: (i) Rocha (2013) que investigou a inserção da temática ambiental nos cursos de formação de professores em Ciências (Biologia, Química, Física) e Matemática da Universidade Federal de Goiás (UFG); (ii) Pitanga (2015) cujo objetivo foi o de investigar a incorporação das questões ambientais no curso de Licenciatura em Química oferecido pela Universidade Federal de Sergipe - campus de São Cristóvão, (iii) Garrido (2016) que analisou a abordagem da EA nos cursos de licenciatura em Ciências Biológicas e de Pedagogia oferecidos por duas universidades públicas situadas no município do Rio de Janeiro-RJ, (iv) Pereira (2016) que analisou a abordagem dos temas ambientais nos currículos dos cursos de licenciatura oferecidos pelo Instituto Federal do Norte de Minas Gerais; (v) Leite (2019) que analisou as estratégias utilizadas para inserção da temática ambiental em cursos de Licenciatura em Física, oferecidos por Instituições de Ensino Superior localizadas no estado de São Paulo.

Uma vez que a abordagem dos temas ambientais fica, frequentemente, restrita às disciplinas de áreas do conhecimento que, tradicionalmente, se relacionam ao meio ambiente, tais como as Ciências Biológicas e a Geografia (SANTOS; CARVALHO; LEVINSON, 2014), essas reflexões chamaram nossa atenção para a incorporação da temática ambiental em cursos responsáveis pela formação de professores de Física. É interessante salientar que a Física é uma área do conhecimento que também oferece oportunidades para o desenvolvimento de atividades educativas centradas na temática ambiental (WATANABE, 2012; REIS; SILVA; FIGUEIREDO, 2015; RIBEIRO, 2018; RIBEIRO; WATANABE; 2019; LEITE, 2019), o que viabiliza a sua presença em um curso de Licenciatura em Física.

A partir desse cenário, fomos motivados a realizar uma pesquisa com o intuito de analisar como as recomendações da legislação brasileira para a inserção da EA e da temática 
ambiental nos cursos de formação docente se materializam em Projetos Pedagógicos de cursos de formação de professores de Física. Considerando que esses Projetos Pedagógicos devem estar alinhados às recomendações fixadas pelas Diretrizes Curriculares para a formação de professores, também reconhecemos a relevância de analisar esses documentos com o intuito de compreender como tais diretrizes se apropriam do discurso da legislação brasileira que trata da inserção da EA nos cursos de licenciatura.

Assim, analisamos a Resolução CNE/CP 2/2015 - que institui as Diretrizes Curriculares Nacionais (DCN) para a formação inicial em nível superior (cursos de licenciatura, cursos de formação pedagógica para graduados e cursos de segunda licenciatura) e para a formação continuada - e a Deliberação CEE n ${ }^{\circ} 111 / 2012$ - que fixou as Diretrizes Curriculares Complementares para a formação de professores nos Cursos de Graduação em Pedagogia, Normal Superior e Licenciaturas, oferecidos pelos estabelecimentos de Ensino Superior do estado de São Paulo. Além desses documentos, selecionamos os Projetos Pedagógicos de dois cursos de Licenciatura em Física oferecidos por Instituições de Ensino Superior (IES) federais e estaduais, localizadas no estado de São Paulo.

Dessa forma, esse trabalho possui o seguinte problema de pesquisa: as recomendações para a inserção da Educação Ambiental na formação inicial de professores materializam-se nos Projetos Pedagógicos dos cursos de Licenciatura em Física oferecidos por duas Instituições de Ensino Superior públicas localizadas no estado de São Paulo? Para responder esse questionamento, apresentamos os seguintes objetivos:

- Identificar as recomendações dadas pela Resolução CNE/CP 2/2015 e pela Deliberação CEE $n^{\circ} 111 / 2012$ para a abordagem da EA e da temática ambiental nos cursos de licenciatura;

- Analisar como os cursos de Licenciatura em Física se apropriam das recomendações apresentadas na Resolução CNE/CP 2/2015 e na Deliberação CEE n 111/2012 para incorporar aspectos da temática ambiental e/ou EA em seus currículos;

Tendo apresentado a justificativa, o problema e os objetivos da pesquisa, no próximo tópico especificamos os aspectos metodológicos empregados para o levantamento e a análise dos dados. 


\section{ASPECTOS METODOLÓGICOS}

Esta é uma pesquisa qualitativa (BOGDAN; BIKLEN, 1994; DENZIN; LINCOLN, 2006) de natureza documental (ALVES-MAZZOTTI; GEWANDSZNAJDER, 2000). Os dados foram levantados através da leitura da Resolução CNE/CP 2/2015 e da Deliberação CEE n. ${ }^{\circ} 111 / 2012$ e dos Projetos Pedagógicos de dois cursos de Licenciatura em Física oferecidos por duas IES públicas situadas no estado de São Paulo.

A opção por esses cursos foi incentivada pelo número expressivo de pesquisas em EA provenientes de Instituições de Ensino Superior situadas no estado de São Paulo (CARVALHO et al., 2016), fato que pode incentivar a abordagem do tema nos cursos oferecidos por IES localizadas nesse estado. Considerando que esses cursos devem obedecer às Diretrizes Curriculares para a formação de professores apresentadas pela Resolução CNE/CP 2/2015 e pela Deliberação CEE n. ${ }^{\circ} 111 / 2012$, entendemos que esses documentos também deveriam ser submetidos à análise, uma vez que seria relevante identificar as suas orientações para o tratamento da EA e da temática ambiental nos cursos de licenciatura.

Na leitura dessa Resolução e Deliberação, identificamos recomendações distintas para a inserção da EA e da temática ambiental na formação de professores. Considerando que todos os cursos de formação de professores oferecidos a nível nacional devem atender à Resolução CNE/CP 2/2015 e que os cursos de licenciatura oferecidos por IES estaduais paulistas são subsidiados, adicionalmente, pela Deliberação CEE n. ${ }^{\circ}$ 111/2012, indagamos como a EA e a temática ambiental são exploradas em um curso de Licenciatura em Física que obedece à Resolução em comparação àquele que, além desta, também deve atender à Deliberação. Por isso, optamos pela análise dos Projetos Pedagógicos de dois cursos de Licenciatura em Física: um dos mais tradicionais do estado, oferecido por uma instituição estadual paulista, e outro mais recente, oferecido por uma instituição federal.

Esse material foi analisado com base no referencial de Michel Foucault (1926-1984), com a mobilização dos conceitos de formação discursiva, poder e sujeito, explicitados a seguir.

\section{Conceitos foucaultianos para a Análise do Discurso}

Em meados do século XX, pautado em um estudo discursivo das áreas da loucura e sexualidade, Michel Foucault (1926-1984) rompe com as definições clássicas de conceitos 
vigentes, apresentando uma nova concepção sobre o sujeito e a história que embasarão a construção de sua teoria. O filósofo francês propõe uma mudança de abordagem da "história tradicional" (história dos pensamentos) - cujos acontecimentos constituem uma continuidade ininterrupta e são resultado da consciência do sujeito dotado de subjetividade - para uma "nova história" (história das ideias), marcada pelas descontinuidades, rupturas e dispersões que descentralizam o sujeito.

A intenção deste intelectual não foi a de construir uma teoria do sujeito, mas sim entender como ele se constitui. Para tanto, é essencial que se compreenda os conceitos foucaultianos de enunciado, discurso e formação discursiva.

O enunciado é da ordem do acontecimento e por isso é singular, é marcado pela descontinuidade e está intrinsicamente relacionado com o contexto e período histórico no qual está inserido e, embora exista uma relação direta entre enunciado e signo, não deve ser confundido com uma palavra ou frase, ou seja, não é uma estrutura. Nas palavras de Foucault, o enunciado é:

\begin{abstract}
Mais que um elemento entre outros, mais que um recorte demarcável em um certo nível de análise, trata-se, antes, de uma função que se exerce verticalmente, em relação às diversas unidades, e que permite dizer, a propósito de uma série de signos, se elas estão aí presentes ou não. [...] é uma função de existência que pertence, exclusivamente, aos signos, e a partir da qual se pode decidir, em seguida, pela análise ou pela intuição, se eles "fazem sentido" ou não, segundo que regra se sucedem ou se justapõem, de que são signos, e que espécie de ato se encontra realizado por sua formulação (oral ou escrita) (FOULCAULT, 2008, p. 98).
\end{abstract}

Os diferentes enunciados constituem uma rede que mantém uma relação constante e, estando em conjunto, constituem o discurso. Na perspectiva foucaultiana, assim como o enunciado, o discurso também é histórico e sofre constantes transformações que dependem dessa temporalidade, o que acaba interferindo em seu sentido. Em consequência, os discursos “[...] não são, como se poderia esperar, um puro e simples entrecruzamento de coisas e de palavras: trama obscura das coisas, cadeia manifesta, visível e colorida das palavras" (FOUCAULT, 2008, p. 54). Mais do que isso, devem ser compreendidos como uma prática que tem a capacidade de formar os objetos de que se fala e que, embora sejam constituídos por signos, “[...] o que fazem é mais que utilizar esses signos para designar coisas. É esse mais que os torna irredutíveis à língua e ao ato da fala. É esse "mais" que é preciso fazer aparecer e que é preciso descrever" (FOUCAULT, 2008, p. 55). 
Levando em conta esses argumentos, o discurso é definido por Foucault como: "um conjunto de enunciados, na medida em que se apoiem na mesma formação discursiva" (FOUCAULT, 2008, p. 132). De acordo com o filósofo, “[...] essa formação agrupa toda uma população de conhecimentos enunciativos. [...] Ela evidencia, dentre os fenômenos da enunciação, as relações que até então permaneciam na sombra e não se encontravam imediatamente transcritas na superfície dos discursos" (FOUCAULT, 2001, p. 106).

Para chegar à definição de formação discursiva, Foucault questiona se é possível dar uma unidade ao discurso e então, examina quatro hipóteses a fim de responder este questionamento. Após constatar que o objeto do discurso sofre diversas modificações com o passar do tempo; que não existe uma regularidade na forma, no tipo e no encadeamento dos enunciados em um discurso específico; que ao mesmo discurso estão atrelados inúmeros e diferentes conceitos; que as teorias não são imutáveis, o filósofo conclui que um discurso é melhor caracterizado pela dispersão do que pela homogeneidade. Então, ao sistema de dispersão associa-se uma formação discursiva que descreve sua regularidade:

No caso em que se puder descrever, entre um certo número de enunciados, semelhante
sistema de dispersão, e no caso em que entre os objetos, os tipos de enunciação, os
conceitos, as escolhas temáticas, se puder definir uma regularidade (uma ordem,
correlações, posições e funcionamentos, transformações), diremos, por convenção,
que se trata de uma formação discursiva (FOUCAULT, 2008, p. 43, grifo do autor).

Tendo definido o que Foucault determina de Enunciado, Discurso e Formação Discursiva, temos os elementos para compreender a definição do filósofo para o sujeito e para as relações de poder que permeiam as relações sociais. Para Foucault, o discurso é responsável por formar os objetos dos quais se fala, da mesma maneira que define o sujeito e o altera em diferentes momentos e circunstâncias históricas. Para justificar essa constatação, o autor retorna ao passado para demonstrar que o sujeito da loucura é definido de maneiras variadas em contextos sociais e históricos diversificados. $\mathrm{Na}$ análise proposta, ele conclui que:

[...] as diversas modalidades de enunciação, em lugar de remeterem à síntese ou à função unificante de um sujeito, manifestam sua dispersão: nos diversos status, nos diversos lugares, nas diversas posições que pode ocupar ou receber quando exerce um discurso, na descontinuidade dos planos de onde fala (FOUCAULT, 2008, p. 61).

Com isso, Foucault destaca que o sujeito "[...] não é estabelecido pela atividade sintética de uma consciência idêntica a si, muda e anterior a qualquer palavra, mas pela especificidade de 
uma prática discursiva" (FOUCAULT, 2008, p. 61, grifo nosso). É importante ressaltar que o discurso que determina o sujeito está diretamente vinculado à posição que ocupa na sociedade. Em outras palavras, podemos dizer que a posição ocupada pelo sujeito designa o que deve e o que não deve ser dito a seu respeito.

Outro aspecto relevante da teoria foucaultiana sobre o sujeito relaciona-se ao campo das interações sociais. Para Foucault, a interação entre os sujeitos que ocupam diferentes posições são acompanhadas por uma relação de poder, um conjunto de forças que compõe todas as relações humanas, ou seja, constitui qualquer relação social. Conforme destacado pelo filósofo, desde que haja uma relação de poder haverá, também, a possibilidade da resistência, já que "[...] nunca somos pegos na armadilha do poder: sempre podemos modificar-lhe o domínio, em determinadas condições e segundo uma estratégia precisa" (FOUCAULT, 2001, p. 200).

Então, embora seja um ser social, constituído pelo contexto histórico e legitimado pelo discurso e pela posição que ocupa, o sujeito não está totalmente submisso, já que, ao mesmo tempo que pode submeter-se ao discurso que o determina, possui condições de rebelar-se contra ele. Por isso, o lugar ocupado pelo sujeito "[...] em vez de ser definido de uma vez por todas e de se manter uniforme ao longo de um texto, de um livro ou de uma obra, varia - ou melhor, é variável o bastante para poder continuar, idêntico a si mesmo, através de várias frases, bem como para se modificar a cada uma" (FOUCAULT, 2008, p. 107).

Sendo assim, consideramos o referencial foucaultiano importante para a análise dos discursos da Resolução CNE/CP 2/2015, da Deliberação CEE n 111/2012 e dos Projetos Pedagógicos dos dois cursos de Licenciatura em Física selecionados. Reconhecemos nesse referencial elementos para compreender como as recomendações para a inserção da EA e da temática ambiental nos cursos de formação de professores se materializam nesses documentos.

\section{A EDUCAÇÃO AMBIENTAL NA FORMAÇÃO INICIAL DE PROFESSORES: O QUE DIZEM AS DIRETRIZES PARA A FORMAÇÃO DOCENTE DE ÂMBITO NACIONAL E ESTADUAL?}

Uma das iniciativas no âmbito legislativo que causou grande impacto nos cursos de licenciatura foi a aprovação, pelo Conselho Nacional de Educação $(\mathrm{CNE})^{1}$, das Resoluções

\footnotetext{
1 Órgão colegiado integrante do Ministério da Educação composto pelas Câmaras de Educação Básica e de Educação Superior com a finalidade de colaborar na formulação da Política Nacional de Educação e exercer atribuições normativas, deliberativas e de assessoramento ao Ministro da Educação, de forma a assegurar a participação da sociedade no aperfeiçoamento da educação nacional.
} 
CNE/CP 1/2002 e CNE/CP 2/2002, que instituem as DCN para a Formação de Professores da Educação Básica. O Art. 1. ${ }^{\circ}$ da Resolução CNE/CP 1/2002 apresenta que as DCN “[...] constituem-se de um conjunto de princípios, fundamentos e procedimentos a serem observados na organização institucional e curricular de cada estabelecimento de ensino e aplicam-se a todas as etapas e modalidades da educação básica” (BRASIL, 2002, p. 1).

Essas DCN apresentam vários princípios orientadores para a reformulação dos cursos de formação de professores. A necessidade de construção de um Projeto Pedagógico específico para os cursos de licenciatura que garantisse a eles uma identidade própria em relação ao bacharelado; a aproximação entre as instituições de formação de professores e os sistemas de ensino da Educação Básica; a articulação entre teoria e prática e a integralização dos cursos de formação de professores em uma carga horária de 2800 horas, são alguns dos aspectos enfatizados na Resolução CNE/CP 1/2002.

Em 2015, as referidas diretrizes passaram por uma atualização e, em relação à Resolução anterior, a Resolução CNE/CP 2/2015 destaca a ampliação das diretrizes para a formação continuada do docente e o enfoque para a necessária valorização dos profissionais do magistério que atuarão da Educação Básica. Além disso, propõe para a formação inicial: a ampliação da carga horária dos cursos para 3.200 horas a ser integralizada em, no mínimo, 4 anos e apresenta uma série de expectativas para o egresso. É reforçada a importância da relação teoria-prática e da inserção do licenciando no ambiente escolar, além de propor a aproximação entre as instituições de ensino superior e de Educação Básica para a elaboração do projeto de formação por meio da realização de Fóruns Estaduais e Distrital Permanentes de Apoio à Formação Docente, em regime de cooperação e colaboração entre essas instituições.

$\mathrm{Na}$ análise desses documentos, identificamos recomendações para a abordagem da temática ambiental nos cursos de formação de professores apenas na Resolução $\mathrm{CNE} / \mathrm{CP}$ 2/2015. O inciso VI do Art. 6. ${ }^{\circ}$ da Resolução CNE/CP 2/2015 afirma que os cursos de formação inicial e continuada de profissionais do magistério devem contemplar: "Questões socioambientais, éticas, estéticas e relativas a diversidade étnico-racial, de gênero, sexual, religiosa, de faixa geracional e sociocultural como princípios de equidade" (BRASIL, 2015, p. 6, grifos nossos). Ao tratar das competências do egresso dos cursos de licenciatura, destaca-se, dentre outros aspectos, que o mesmo deverá estar apto a: "demonstrar consciência da diversidade, respeitando as diferenças de natureza ambiental-ecológica, étnico-racial, de 
gêneros, de faixas geracionais, de classes sociais, religiosas, de necessidades especiais, de diversidade sexual, entre outras" (BRASIL, 2015, p. 8, grifos nossos).

Mesmo respeitando a autonomia pedagógica das IES responsáveis por oferecer os cursos de licenciatura e considerando a diversidade nacional, diretrizes para a formação inicial e continuada dos docentes devem ser mantidas. Por isso, o Art. 12 propõe que esses cursos sejam estruturados em torno de três núcleos ${ }^{2}$. O primeiro abarca a "pesquisa e estudo das relações entre educação e trabalho, educação e diversidade, direitos humanos, cidadania, educação ambiental, entre outras problemáticas centrais da sociedade contemporânea" (BRASIL, 2015, p. 10, grifos nossos). O segundo núcleo engloba a "aplicação, ao campo da educação, de contribuições de conhecimentos, como o pedagógico, o filosófico, o histórico, o antropológico, o ambiental-ecológico, o psicológico, o linguístico, o sociológico, o político, o econômico, o cultural, entre outros" (BRASIL, 2015, p. 10, grifos nossos).

Embora a Constituição Federal e a PNMA destacassem, ainda na década de 1980, a necessidade de que a EA fosse inserida em todos os níveis de ensino, é apenas em 1999 que a PNEA faz referência específica à presença desse tema nos cursos de formação de professores. Apesar disso, o discurso das DCN para as licenciaturas instituídas em 2002 não apresenta recomendações para a abordagem da EA ou da temática ambiental nos cursos de licenciatura. Avaliamos que isso pode ser resultado do enunciado da formação de professores que ainda vigorava na época. Apesar de a Lei de Diretrizes e Bases da Educação Nacional (LDB), promulgada em 20 de dezembro de 1996, ter ocasionado uma série de impactos na estrutura dos cursos de licenciatura, as concepções oriundas do modelo de formação " $3+1$ ” estavam sendo desconstruídas naquele momento. Com isso, no início do século XXI ainda vigorava um discurso que revelava o embasamento conceitual e científico como uma garantia para a formação de um bom professor. Sendo assim, entendemos que, ao se apropriar desse tipo de enunciado, os discursos provenientes das DCN para a formação de professores da época desconsideravam a importância de aspectos relacionados à EA ou à temática ambiental para a formação do professor.

Entretanto, conforme destacado por Foucault, os enunciados estão associados ao contexto e ao período histórico em que são elaborados e, por isso, são passíveis de mudanças e

\footnotetext{
2 (i) Núcleo de estudos de formação geral, das áreas específicas e interdisciplinares, e do campo educacional, seus fundamentos e metodologias, e das diversas realidades educacionais; (ii) Núcleo de aprofundamento e diversificação de estudos das áreas de atuação profissional, incluindo os conteúdos específicos e pedagógicos e a pesquisa priorizadas pelo projeto pedagógico das instituições, em sintonia com os sistemas de ensino e (iii) Núcleo de estudos integradores para enriquecimento curricular.
} 
alterações. Com isso, evidenciamos na Resolução CNE/CP 2/2015, o discurso que determina a inserção da EA e de aspectos da temática ambiental nos cursos de licenciatura. Certamente, uma influência da publicação das DCNEA em 2012 que determinam, explicitamente, que a EA esteja presente nesses cursos, trazendo orientações mais claras da maneira como deve ocorrer esse processo. Além disso, nos 13 anos entre a publicação dessas duas diretrizes, as discussões e pesquisas tanto de EA, quanto de formação de professores, passaram por um "amadurecimento" influenciando a construção de um novo enunciado sobre a formação do professor. Ademais, destacamos que a problemática ambiental recebeu um destaque ainda mais significativo na última década, fator que pode ter influenciado a elaboração desse novo discurso da Resolução CNE/CP 2/2015 que apresenta explicitamente a necessidade de que a EA e a temática ambiental sejam exploradas nos cursos de licenciatura.

Além das diretrizes para a formação de professores estabelecidas em âmbito nacional, cabe ressaltar as diretrizes estaduais que visam o atendimento às especificidades dos estados. Em São Paulo, por exemplo, o Conselho Estadual de Educação (CEE) ${ }^{3}$, por meio da Deliberação CEE n. ${ }^{\circ}$ 111/2012, fixou as Diretrizes Curriculares Complementares para os cursos de formação de professores oferecidos pelos estabelecimentos de Ensino Superior vinculados ao sistema estadual. Além de determinar a carga horária de 3200h para a integralização dos cursos para formação inicial de professores de Educação Básica em nível superior, essa Deliberação indicou que, além das $400 \mathrm{~h}$ de estágio supervisionado, esses cursos deveriam dedicar $30 \%$ da carga horária total à formação didático-pedagógica do futuro professor. Em 2017, foi publicada a Deliberação CEE n. ${ }^{\circ}$ 154/2017 que apresenta uma revisão da Deliberação CEE n. ${ }^{\circ}$ 111/2012 com a finalidade de compatibilizá-la com a Resolução CNE/CP 02/2015. A principal alteração foi a redistribuição da carga horária de 3200h dos cursos de licenciatura, embora as $400 \mathrm{~h}$ de estágio supervisionado tenham sido mantidas.

Em relação ao discurso das deliberações propostas pelo Conselho Estadual de Educação de São Paulo, constatamos que a inserção de aspectos da temática ambiental é enfatizada apenas para os cursos de formação de professores que atuarão na Educação Infantil e nos anos iniciais do Ensino Fundamental. Como destacado pelo inciso V do Art. 5, na formação de docentes que atuarão nestes níveis de ensino devem ser valorizados:

\footnotetext{
${ }^{3}$ Órgão normativo, deliberativo e consultivo do sistema educacional público e privado paulista que estabelece as regras para todas as escolas de todas as redes - estaduais, municipais e particulares - de educação infantil, ensino fundamental, ensino médio e profissional, seja presencial ou a distância, além de orientar e credenciar os cursos das instituições de ensino superior públicas do estado de São Paulo.
} 
Estudos de Ciências Naturais incluindo a compreensão de fenômenos do mundo físico e natural, dos seres vivos, do corpo humano como sistema que interage com o ambiente, da condição de saúde e da doença resultantes do ambiente físico e social, do papel do ser humano nas transformações ambientais e das suas consequências para todos os seres vivos (SÃO PAULO, 2012, p. 2).

Porém, esse não seria um aspecto levado em consideração pelos cursos de formação de professores de Física oferecidos por IES do estado de São Paulo, já que a Física é uma disciplina do Ensino Médio. Quando analisamos as recomendações para a formação de docentes que atuarão nesta etapa da Educação Básica, a temática ambiental não é mencionada.

Mesmo sendo exigido pela legislação brasileira, a Deliberação CEE n 111/2012 não faz referência à abordagem da EA ou da temática ambiental nos cursos responsáveis por formar docentes que atuarão no Ensino Médio - caso do professor de Física. Devido ao fato de ser considerada um complemento à Resolução CNE 2/2015 (que já destaca a inserção da EA nos cursos de licenciatura), avaliamos que as diretrizes propostas pelo CEE-SP tenham priorizado aspectos não abordados pelas Resolução CNE 2/2015, buscando atender às especificidades e necessidades da educação do estado de São Paulo.

Tendo apresentado as recomendações fixadas pelas diretrizes e deliberações analisadas, principalmente o que se refere à inserção da EA nos cursos de formação de professores, o próximo item apresenta a análise dos Projetos Pedagógicos de dois cursos de Licenciatura em Física oferecidos por duas IES públicas localizadas no estado de São Paulo.

\section{A EDUCAÇÃO AMBIENTAL E OS CURSOS DE LICENCIATURA EM FÍSICA LOCALIZADOS NO ESTADO DE SÃO PAULO: O QUE DIZEM SEUS PROJETOS PEDAGÓGICOS?}

O curso de Licenciatura em Física $1\left(\mathrm{FLI}_{1}\right)$ é oferecido por uma Instituição Federal localizada na região noroeste do estado de São Paulo que iniciou as suas atividades educacionais no $2^{\circ}$ semestre de 2010 (PPC FLI ${ }_{1}$ ). Esse curso passou a ser ofertado neste estabelecimento de ensino de forma presencial, no período noturno, no primeiro semestre de 2014, possui duração de 8 semestres que integralizam a carga horária de 3267 horas, oferece 40 vagas anuais e os discentes são selecionados por meio do Sistema de Seleção Unificada SISU do MEC (PPC FLI 1,2017$)$.

De acordo com o Projeto Pedagógico desse curso, a inclusão social e a promoção do desenvolvimento regional sustentável são “[...] tarefas centrais a serem cumpridas, atentando 
para a diversidade cultural e defesa do meio ambiente, promovendo a interação do saber acadêmico e o popular" (PPC FLI 1 , 2017, p. 229). Nessa perspectiva, a PNEA é citada para confirmar a necessidade de que a EA seja "[...] desenvolvida como uma prática educativa integrada, contínua e permanente também no ensino superior" (PPC FLI ${ }_{1}, 2017$, p. 35). Além disso, destaca-se que aspectos da temática ambiental e da EA são abordados pelo curso em conformidade ao que é prescrito pela Resolução CNE 2/2015.

De acordo com o referencial foucaultiano, os sujeitos estabelecem uma relação de poder, sendo que as posições ocupadas que determinarão quem estabelecerá sobre o outro a sua noção de verdade. No caso dos documentos analisados, podemos dizer que é estabelecida uma relação de poder das normas e diretrizes para com os Projetos Pedagógicos dos cursos de licenciatura.

A formação discursiva da Educação Ambiental estabelece que a EA e a temática ambiental sejam inseridas em todos os níveis de ensino, inclusive nos cursos de formação de professores. A legislação brasileira e as Diretrizes Curriculares para a formação de professores reforçam esse discurso que, por sua vez, é apropriado pelo Projeto Pedagógico do curso FLI 1 . Ao reforçar que o curso de Licenciatura em Física está alinhado às recomendações da PNEA e da Resolução CNE 2/2015, reconhecemos que esse PPC se apreende desses discursos devido à posição que ocupa em relação às leis e às diretrizes.

Ao se apropriar desse discurso, os enunciados do PPC do curso $\mathrm{FLI}_{1}$ revelam o esforço de integrar a dimensão ambiental às atividades de ensino e de extensão. Em uma passagem do documento, identificamos que um excerto revela que "[...] a dimensão ambiental integrará tacitamente parte do Conteúdo Programático de todas as disciplinas do curso, devendo ser trabalhada de modo articulado aos demais itens desses conteúdos” (PPC FLI 1 , 2017, p. 35). Além disso, é acrescentado que:

[...] prevê-se neste curso a integração da educação ambiental às disciplinas do curso de modo transversal, contínuo e permanente (Decreto $\mathrm{N}^{\circ} 4.281 / 2002$ ), por meio da realização de atividades curriculares e extracurriculares, desenvolvendo-se este assunto durantes todos os semestre de forma mais especifica nas disciplinas: LITS1 (Leitura, Interpretação e Produção de Texto), PSIS3 (Psicologia da Educação), CDIS2 (Cálculo Diferencial e Integral I), FILS1 (Filosofia da Educação), Mecânica (MECS2), Eletromagnetismo I (EMGS5), Termodinâmica (TERS4), Didática (DIDS4), Prática Pedagógica (PPDS4), Legislação Educacional (LEGS5), História da Educação (HEDS2), Direitos Humanos e Cidadania (DHCS7), Práticas de Ensino de Física I, II, III, IV (PEFS5, PEFS6, PEFS7, PEFS8), bem como nas práticas experimentais, projetos, palestras, apresentações, programas, ações coletivas, dentre outras possibilidades (PPC FLI 1,2017 , p. 35). 
De fato, ao analisar a grade curricular desse curso, constatamos que diferentes aspectos da temática ambiental constituem as ementas das disciplinas discriminadas no excerto anterior (PPC FLI 1,2017 , p. 35). Verificamos que uma parte dessas disciplinas indica as contribuições do processo educativo para a reconstrução da relação sociedade-Natureza ou explora os fundamentos, diretrizes e políticas de Educação Ambiental e a sua inserção no espaço escolar. Outro conjunto de disciplinas oferece subsídios teóricos e metodológicos para a abordagem da temática ambiental em aulas de Física na Educação Básica. Por fim, um grupo de disciplinas propõe a análise, descrição e/ou modelagem do meio ambiente e dos fenômenos ambientais por meio de conceitos da Física e de outras áreas do conhecimento (como Matemática e Química) ou explora os impactos ambientais causados pelo desenvolvimento tecnológico.

Além de estar presente nas atividades de ensino, destaca-se no PPC do curso FLI que a temática ambiental também é explorada em atividades de extensão universitária, principalmente porque:

A natureza das ações de extensão favorece o desenvolvimento de atividades que envolvam a Educação das Relações Étnico-Raciais e para o Ensino de História e Cultura Afro-Brasileira e Africanas, conforme exigência da Resolução $\mathrm{CNE} / \mathrm{CP} \mathrm{n}^{\circ}$ 01/2004, além da Educação Ambiental, cuja obrigatoriedade está prevista na Lei 9.795/1999 (PPC FLI, p. 229, grifo nosso).

Notamos que diferentes passagens desse PPC enfatizam que o curso $\mathrm{FLI}_{1}$ está de acordo com o que é especificado por normas, diretrizes e leis. Destacamos que a utilização frequente dos termos "exigência" e "obrigatoriedade" revelam que as posições ocupadas são reconhecidas e bem delimitadas, influenciando a apropriação de um discurso já estabelecido.

Entretanto, é interessante destacar que, além de os aspectos da temática ambiental e da EA estarem presentes no referido PPC a fim de atender a uma exigência da legislação, identificamos outros elementos que revelam o reconhecimento das contribuições do tema para a formação de um professor de Física. O coordenador do curso, quando entrevistado para a realização de uma etapa posterior dessa investigação ${ }^{4}$, destaca a valorização desta temática pelo corpo docente que atua no curso:

\footnotetext{
${ }^{4}$ Para levantar os dados para a construção dessa investigação, além da análise dos Projetos Pedagógicos dos cursos de Licenciatura em Física selecionados, também realizamos entrevistas com os coordenadores desses cursos. Entretanto, neste trabalho optamos por concentrar as discussões relativas às análises desses documentos e apresentamos as considerações desses professores apenas para complementar as discussões.
} 
Além de atender a legislação essa abordagem mais efetiva da questão ambiental nas disciplinas foi fruto de um trabalho realizado pelo NDE [Núcleo Docente Estruturante] que reconhece a importância deste tema para a formação do professor (Coordenador do curso $\mathrm{FLI}_{1}$, grifos nossos).

Por sua vez, o curso de Licenciatura em Física $2\left(\mathrm{FLI}_{2}\right)$ é oferecido por uma universidade estadual localizada em um município do interior de São Paulo, também da região noroeste do estado. A instituição foi fundada em 1962, sendo que o curso de Licenciatura em Física passou a ser ofertado a partir de 1967. É oferecido de forma presencial nos períodos diurno e noturno, sendo que o primeiro possui duração de 8 semestres, carga horária de 3330 h e oferta 155 vagas anuais $^{5}$, enquanto que o segundo possui duração de 10 semestres que integralizam a carga horária de 3267 h e oferta 40 vagas anuais. Para ambos, a seleção dos alunos se dá por meio Vestibular Nacional da instituição (PPC FLI 2,2017$)^{6}$.

As referências à temática ambiental e à EA são escassas no Projeto Pedagógico do curso $\mathrm{FLI}_{2}$. Ao tratar do perfil do egresso afirma-se nesse documento que, por ser uma ciência natural, a Física apresenta um caráter multidisciplinar e, por isso, pode contribuir para estudos de diversas áreas, inclusive do meio ambiente e do clima. Por isso, é apresentado que:

A formação do Físico deve, portanto, ser tal que possa fazê-lo capaz de reconhecer padrões e explicar fenômenos da natureza, prevendo ocorrências sempre que possivel; e ainda, abordar e tratar problemas novos - sejam eles fenômenos naturais ou projetos especificos em sua área de trabalho - a partir de conhecimentos sólidos $e$ atualizados em Física (PPC FLI 2,2018 , p. 5, grifos nossos).

Todavia, constatamos que esse curso não oferece os subsídios necessários para o alcance desse objetivo. Do rol de disciplinas do curso $\mathrm{FLI}_{2}$, identificamos apenas uma que se articula à temática ambiental ("Fontes Alternativas de Energia”). A sua ementa envolve o estudo de fontes de energia renovável e combustíveis alternativos, como o Biodiesel, o Bioetanol, as células solares, as Usinas Nucleares e Eólicas. Além disso, também explora os estudos de impactos ambientais relacionados com a produção de energia elétrica em larga escala.

Com essa análise, compreendemos que o curso $\mathrm{FLI}_{2}$ optou pela abordagem da temática ambiental de forma muito mais limitada quando comparado ao curso FLI 1 . Nesse caso, compreendemos que essa abordagem pode ser resultado do discurso da Deliberação CEE $n^{\circ}$ 111/2012. Conforme explicitado no tópico anterior, constatamos que a referida deliberação não

\footnotetext{
${ }^{5} \mathrm{O}$ ingresso no curso de Física do período diurno é realizado de forma conjunta com outros dois cursos e os alunos optam por uma das carreiras oferecidas após três semestres dentro da Universidade.

${ }^{6}$ Os mesmos foram considerados um único curso, por possuírem um único Projeto Pedagógico.
} 
apresenta recomendações explícitas para da abordagem da temática ambiental nos cursos responsáveis pela formação dos professores que atuarão no Ensino Médio. Com isso, esse fato pode ser tomado como uma justificativa para a opção do curso $\mathrm{FLI}_{2}$ em explorar a questão ambiental de forma pontual em sua grade curricular.

Por outro lado, recorremos a outro elemento do referencial foucaultiano que nos auxilia a compreender a diferença da materialização dos discursos das leis e diretrizes em ambos PPC dos cursos de Licenciatura em Física analisados. Apesar de as posições ocupadas pelos sujeitos determinarem a existência de uma relação de poder, Foucault indica a possibilidade de resistir ao discurso imposto, ocasionando tensões. A resistência pode modificar o domínio do discurso e, por isso, o lugar não é estático. Por isso, compreendemos que a apropriação dos discursos das Diretrizes Curriculares para a formação de professores pelos Projetos Pedagógicos não pode ser compreendida como um "processo linear".

$\mathrm{O}$ curso $\mathrm{FLI}_{2}$ não está plenamente em conformidade ao que é exigido pela Resolução CNE 2/2015 no que se refere à EA, uma vez que seu PPC não apresenta qualquer discussão voltada para a Educação Ambiental e a temática ambiental é explorada de forma pontual em apenas uma disciplina. Compreendemos que essa opção seria uma maneira de expor a contrariedade ao que é posto por essas diretrizes, ou seja, uma forma de resistir ao seu discurso. Essa resistência e contrariedade ao que é imposto pela referida Resolução está presente de maneira bastante clara no discurso do coordenador desse curso:

Pode aparecer, inclusive, na pesquisa de vocês, que o coordenador do curso de Física e muitos! E muitos, se não a maioria dos docentes do Instituto de Física, é absolutamente contrária a essa diretriz. Se a gente tivesse sido melhor consultado, a gente teria, obviamente, opinado de forma contrária. Mas, como existe uma regulamentação, ela está aí para ser cumprida a gente está cumprindo, a gente cumpre, mas não somos favoráveis de forma nenhuma (Coordenador do curso $\mathrm{FLI}_{2}$, grifos nossos).

Assim, avaliamos que as recomendações relacionadas à EA apresentadas por essas diretrizes podem ser incompatíveis ao modelo de formação do professor de Física idealizado pela instituição responsável pelo oferecimento do curso $\mathrm{FLI}_{2}$, o que também pode contribuir para a geração de tal resistência.

Outro fato interessante e que pode influenciar o surgimento de tais tensões refere-se ao status de ambas instituições. A instituição federal - responsável por oferecer o curso $\mathrm{FLI}_{1}$ - foi fundada recentemente, sendo que o curso de Licenciatura em Física possui apenas três turmas formadas até o momento. Isso pode indicar que a adequação explícita ao discurso apresentado 
pela Resolução CNE 2/2015 pode ser justificada pela necessidade de garantir a boa avaliação e qualificação do curso. Por outro lado, a instituição estadual - responsável por oferecer o curso $\mathrm{FLI}_{2}$ - é uma das mais tradicionais do estado de São Paulo e possui um dos cursos de Física mais bem qualificados no Brasil, reconhecido pela excelência na formação de Físicos que minimiza o esforço para sua valorização. Entendemos que sua história e trajetória foi responsável pela elaboração de um modelo de formação de professor que tende a valorizar os componentes curriculares voltados para a Física, em detrimento de outros conhecimentos, como aqueles vinculados à EA, por exemplo.

Com essa análise, fica claro que as recomendações para a inserção da EA na formação inicial de professores se materializam nos Projetos Pedagógicos desses dois cursos de Licenciatura em Física de maneiras bastante distintas. Enquanto o curso FLI 1 propõe a inserção da EA de modo transversal e abrangente, abarcando atividades de ensino e de extensão, o curso $\mathrm{FLI}_{2}$ realiza uma inserção simples e pontual por meio de uma única disciplina.

\section{CONSIDERAÇÕES FINAIS}

Neste trabalho, destacamos a necessidade de que a EA e a temática ambiental estejam presentes em todos os cursos de licenciatura, aspecto assegurado pelos instrumentos normativos brasileiros e reafirmado pelas Diretrizes Curriculares Nacionais para a formação de professores institucionalizadas em 2015. A partir dessas informações, analisamos a materialização desses discursos nos Projetos Pedagógicos de dois cursos de Licenciatura Física oferecidos por duas IES públicas localizadas no estado de São Paulo.

Para esta análise, nos embasamos no referencial de Michel Foucault, mobilizando os conceitos de discurso, sujeito e poder. Para Foucault, o sujeito é definido pela posição que ocupa e é essa posição que determinará o que o sujeito irá dizer e, por isso, não importa quem diz, mas sim o lugar de onde se diz.

Por meio desse olhar analítico, é notável a atenção dada à Resolução CNE 2/2015 pelo PPC do curso $\mathrm{FLI}_{1}$, já que as recomendações para a inserção da temática ambiental e da Educação Ambiental na formação de professores são atendidas pelo curso. Em conformidade com o que foi disposto pela referida Resolução, a EA e a temática ambiental são valorizadas em um rol diversificado de disciplinas que, possivelmente, irão explorar diferentes aspectos da temática ambiental de forma interdisciplinar, valorizando a transversalidade do tema. 
Em contrapartida, Foucault também revela que ao poder está associada à resistência, $\mathrm{o}$ que é responsável por gerar conflitos e tensões entre sujeitos que ocupam posições diferentes. Ao analisar o discurso de um instrumento normativo que dispõe de diretrizes que devem ser incorporadas pelos cursos de licenciatura e a maneira como esse discurso é incorporado pelos cursos analisados identificamos movimentos de resistência ao que lhes é imposto, evidenciando a existência de tensões. Há indicativos de que o PPC do curso $\mathrm{FLI}_{2}$ resiste ao discurso imposto pela Resolução CNE 2/2015, uma vez que a temática ambiental é explorada nesse curso de forma muito pontual. Ademais, essa opção do curso $\mathrm{FLI}_{2}$ também pode ser justificada pela ausência dessa recomendação na Deliberação CEE nº 111/2012.

Com isso, analisando os discursos desses Projetos Pedagógicos, concluímos que esses cursos estabelecem uma relação com a temática ambiental e a EA de maneiras muito distintas. Tendo em vista que os docentes desses cursos estão diretamente envolvidos na elaboração dos Projetos Pedagógicos e são os atores centrais nas atividades de pesquisa, ensino e extensão em que a EA e a temática ambiental podem estar presentes, como um desdobramento desta pesquisa esses professores poderiam ser ouvidos com a intenção de compreender como se dá o processo de inserção e abordagem da temática ambiental na Licenciatura em Física.

\section{REFERÊNCIAS}

ALVES-MAZZOTTI, A. J.; GEWANDSZNAJDER, F. O Método nas Ciências Sociais: Pesquisa Quantitativa e Qualitativa. 2. ed. São Paulo: Pioneira, 2000.

BOGDAN, R. C.; BIKLEN, S. K. Investigação qualitativa em educação. Portugal: Porto, 1994.

BRASIL. Lei N. ${ }^{\circ}$ 6.938, de 31 de agosto de 1981. Dispõe sobre a Política Nacional do Meio Ambiente, seus fins e mecanismos de formulação e aplicação, e dá outras providências. Diário Oficial [da] República Federativa do Brasil, Brasília, DF, 1981. Disponível em: https://bit.ly/1YgMNzS.

BRASIL. Constituição da República Federativa do Brasil: texto constitucional promulgado em 5 de outubro de 1988. Brasília: Senado Federal, Coordenação de Edições Técnicas, 2016. Disponível em: https://bit.ly/2ETNGh8.

BRASIL. Lei 9.795, de 27 de abril de 1999. Dispõe sobre a educação ambiental, institui a Política Nacional de Educação Ambiental - PNEA e dá outras providências. Diário Oficial [da] República Federativa do Brasil, Brasília, DF, 1999. Disponível em: https://bit.ly/2GYetpC. 
BRASIL. Ministério da Educação. Conselho Nacional de Educação. Resolução CNE/CP n. 01/2002, de 18 de fevereiro de 2002. Institui Diretrizes Curriculares Nacionais para a Formação de Professores da Educação Básica, em nível superior, curso de licenciatura, de graduação plena. Diário Oficial [da] República Federativa do Brasil, Brasília: MEC/CNE, 2002a. Disponível em: https://bit.ly/2gPm8PY.

BRASIL. Ministério da Educação. Conselho Nacional de Educação. Resolução CNE/CP n. 2/2012, de 15 de junho de 2012. Estabelece as Diretrizes Curriculares Nacionais para a Educação Ambiental. Diário Oficial [da] República Federativa do Brasil, Brasília: MEC/CNE, 2012. Disponível em: https://bit.ly/2K5CYU5.

BRASIL. Ministério da Educação. Conselho Nacional de Educação. Resolução CNE/CP n. 02/2015, de $1^{\text {o }}$ de julho de 2015. Define as Diretrizes Curriculares Nacionais para a formação inicial em nível superior (cursos de licenciatura, cursos de formação pedagógica para graduados e cursos de segunda licenciatura) e para a formação continuada. Diário Oficial [da] República Federativa do Brasil, Brasília: MEC/CNE, 2015. Disponível em: https://bit.ly/2HHTkR7.

CARVALHO, L.M. et al. A educação ambiental no Brasil: análise da produção acadêmica - teses e dissertações. CNPq: Relatório Científico. Rio Claro, UNESP - Rio

Claro, UNICAMP, USP - Ribeirão Preto, 2016. Disponível em: https://bit.ly/3eqjOIg.

CARVALHO, L. M. A Educação Ambiental e a formação de professores. In: Secretaria de Educação Fundamental. Panorama da Educação Ambiental no ensino fundamental. Brasília: MEC; SEF, 2001, 149 p.; p. 55-83. Disponível em: https://bit.ly/2OLdmP7.

CARVALHO, L. M.; SANTOS, W. P.; LEVINSON, R. A Dimensão Política da Educação Ambiental em Investigações de Revistas Brasileiras de Ensino de Ciências. Revista Brasileira de Pesquisa em Educação em Ciências, Belo Horizonte, v. 14, n. 2, p. 199-213, 2014. Disponível em: https://bit.ly/2OezdOt.

DENZIN, N.K; LINCOLN, Y. S. O planejamento da pesquisa qualitativa: teorias e abordagem. Porto Alegre: Artmed, 2006.

FOUCAUlT, M. (2001). Poder e saber. In: MOTTA, M. B. Ditos e escritos IV: Michel Foucault: estratégia, poder-saber. 2. ed. Rio de Janeiro: Forense Universitária. 2001.

FOUCAULT, M. A arqueologia do saber. 7. ed. Rio de Janeiro: Forense Universitária. 2008.

FRACALANZA, H. As pesquisas sobre Educação Ambiental no Brasil e as escolas: alguns comentários preliminares. In: TAGLIEBER, J.E. e GUERRA, A.F.S. (orgs.) Pesquisa em Educação Ambiental: pensamentos e reflexões de pesquisadores em Educação Ambiental. Pelotas: Editora Universitária/UFPel, 2004, p. 55-77. Disponível em: https://bit.ly/2T09UCv.

GARRIDO, L. S. A inserção da Educação Ambiental em cursos de Pedagogia e licenciatura em Ciências Biológicas: caminhos para a interdisciplinaridade? 2016. 184f. Tese (Doutorado Ensino em Biociências e Saúde) - Fundação Oswaldo Cruz, Rio de Janeiro, 2016. Disponível em: https://bit.ly/3eqAdfV. 
GUERRA, A. F. S.; FIGUEIREDO, M. L.; ORSI, R. F. M.; STEUCK, E. R.; CARLETTO, D. L.; DA SILVA, M. P.; LUNA, J. M. F. A ambientalização na Educação Superior: trajetória e perspectivas. In: GUERRA, A. F. S. (Org.). Ambientalização e sustentabilidade nas universidades: subsídios, reflexões e aprendizagens. 1. Ed. Dados eletrônicos, Itajaí: Editora da Univali, 2015.

KITZMANN, D.; ASMUS, M. Ambientalização sistêmica - do currículo ao socioambiente. Currículo sem Fronteiras, Pelotas, v.12, n.1, p. 269-290, 2012. Disponível em: https://bit.ly/3bfXxLo.

LEITE, D. A. R. A temática ambiental na formação inicial de professores: análise de cursos de Licenciatura em Física de Instituições de Ensino Superior localizadas no estado de São Paulo. 2019. 268 f. Tese (Doutorado em Educação) - Universidade Estadual Paulista "Júlio de Mesquita Filho", Rio Claro, 2019. Disponível em: https://bit.ly/2VdbXpM.

MIYAZAWA, G. C. M. C.; FRENEDOZO, R. C.; VIEIRA, R. M. Inserção da temática ambiental em um curso de licenciatura em ciências biológicas: concepções dos docentes e suas práticas pedagógicas. Pesquisa em Educação Ambiental, v.14, n.1, p. 89-110, 2019. Disponível em: https://bit.ly/3bcH2je.

MOTA, J. C.; KITZMANN, D. I. S. O Processo de Ambientalização Curricular na Educação Superior: uma Proposta Metodológica. Cadernos de Pesquisa: Pensamento Educacional, Curitiba, Número Especial, p.318-334, 2018. Disponível em: https://bit.ly/2Ve9aNd.

MOTIN, S. D.; GONGALVES, R. M. T.; CASSINS, D. M. S. O.; SAHEB, D. Educação ambiental na formação inicial docente: um mapeamento das pesquisas brasileiras em teses e dissertações. Investigações em Ensino de Ciências, Porto Alegre, v. 24, n. 1, p. 81-102, 2019. Disponível em: https://bit.ly/3cl7t6r.

OLIVEIRA, M.G.; CARVALHO, L. M. Políticas públicas de formação de professores e de Educação Ambiental: possíveis articulações? Revista Contemporânea de Educação, Rio de Janeiro, v. 7, n. 14, p. 252-275, 2012. Disponível em: https://bit.ly/2AXa1Yw.

PEREIRA, G. N. Produção discursiva sobre questões ambientais no currículo de Licenciatura em Geografia. 2014. 85f. Dissertação (Mestrado em Educação) - Faculdade de Educação da Baixada Fluminense, Universidade do Estado do Rio de Janeiro, Duque de Caxias, 2014. Disponível em: https://bit.ly/3al7qpX.

PITANGA, A. F. A inserção das questões ambientais no curso de Licenciatura em Química da Universidade Federal de Sergipe. 2015. 200 f. Tese (Doutorado em Educação) - Universidade Federal de Sergipe, São Cristóvão, 2015. Disponível em: https://bit.ly/34FoaqF.

REIS, D. A.; SILVA, L. F.; FIGUEIREDO, N. As complexidades inerentes ao tema mudanças climáticas: desafios e perspectivas para o Ensino de Física. Ensaio Pesquisa em Educação em Ciências, Belo Horizonte, v. 17, n. 3, p. 535-554, 2015. Disponível em: https://bit.ly/2OLSIhV. 
RIBEIRO, T. C. Aspectos da complexificação para tratar a entropia nas aulas de Física. 2018. 140 f. Dissertação (Mestrado Nacional Profissional em Ensino de Física) Universidade Federal do ABC, Santo André, 2018.

RIBEIRO, T. C.; WATANABE, G. Apontamentos para propor aulas de ciências mais complexas a partir do tema entropia. Investigación en la Escuela, Sevilla, v. 98, p. 46-67, 2019. Disponível em: https://bit.ly/3ag1FcV.

ROCHA, A. F. V. A inserção da temática ambiental no ensino superior: uma análise nos cursos de formação de professores em Ciências e Matemática da UFG. 2013. 132 p.

Dissertação (Mestrado em Educação em Ciências e Matemática) - Universidade Federal de Goiás, Goiânia, 2013. Disponível em: https://bit.ly/2z3Ferv.

RUSCHEINSKY, A. Périplo pela incorporação da dimensão socioambiental: incertezas, desafios e tensões em trajetórias universitárias. In: RUSCHEINSKY, A.; GUERRA, A. F. S.; FIGUEIREDO, M. L.; LEME, P. C. S.; RANIERI, V. E. L.; DELITTI, W. B. C. (Orgs.). Ambientalização nas instituições de educação superior no Brasil: caminhos trilhados, desafios e possibilidades. São Carlos: EESC/USP, 2014. p. 99-124.

SANTOS, W. L. P.; CARVALHO, L. M.; LEVINSON, R. A dimensão política da educação ambiental em investigações de revistas brasileiras de ensino de ciências. Revista Brasileira de Pesquisa em Educação em Ciências, Belo Horizonte, v. 14, n. 2, p. 199-213, 2014. Disponível em: https://bit.ly/3exRZ0X.

SÃO PAULO. Conselho Estadual de Educação. Deliberação 111/2012. Diário Oficial do estado de São Paulo (DOESP), São Paulo, SP, 3 fev. de 2012, Seção I, p. 46. Disponível em: $<$ https://bit.ly/2vD6GKo $>$.

SÃO PAULO. Conselho Estadual de Educação. Deliberação 154/2017. Diário Oficial do estado de São Paulo (DOESP), São Paulo, SP, 7 jul. 2017, Seção I, p. 38-39. Disponível em: $<$ https://bit.ly/2KtdGyI $>$.

SILVA, T. N.; FARIAS, C. R. O. Análise da inserção das questões ambientais em dois cursos de Licenciatura em Química de uma universidade pública. Investigações em Ensino de Ciências, Porto Alegre, v. 22, n. 3, p. 80-101, 2017. Disponível em: https://bit.ly/3algHyg.

WATANABE, G. Aspectos da complexidade: contribuições da Física para a compreensão do tema ambiental. 2012. 246 p. Tese (Doutorado em Ensino de Ciências) - Universidade de São Paulo, São Paulo, 2012. Disponível em: https://bit.ly/2zHWTET.

ZUIN, V. G.; FARIAS, C. R.; FREITAS, D. A ambientalização curricular na formação inicial de professores de Química: considerações sobre uma experiência brasileira. Revista

Electrónica de Enseñanza de las Ciencias, Vigo, v.8, n. 2, p. 552-570, 2009. Disponível em: https://bit.ly/2oZvBF4. 